\title{
“LANZAROTE É MINHA JANGADA DE PEDRA": JOSÉ SARAMAGO E A ESCRITA MEMORIALÍSTICA DO EXÍLIO
}

\author{
Rodrigo Xavier \\ (Universidade Tecnológica Federal do Paraná)
}

\section{RESUMO}

O presente artigo propõe uma leitura dos primeiros Cadernos de Lanzarote, escritos pelo português José Saramago e publicados entre os anos de 1993 e 1997, ensaiando rascunhar uma possível relação entre o papel de intelectual exercido pelo escritor e a composição de uma literatura autobiográfica que se constitui por meio de um diferenciado aprendizado da memória, a partir de seu exílio na ilha espanhola. Os escritos de Edward Said nortearão as discussões sobre o exílio propostas neste trabalho, assim como as obras de Philippe Lejeune se apresentam no diálogo sobre autobiografia e memória.

PALAVRAS-CHAVE: José Saramago e a autobiografia, literatura e memória, literatura e exílio.

\section{ABSTRACT}

The current paper offers a reading of the initial Saramago's Diaries, written by the Portuguese José Saramago and published between the years of 1993 and 1997, as it rehearses drafting a possible relation between the role of the intellectual, as performed by the writer and the composition of an autobiographical literature. This latter is constituted by means of a unique acquisition and learning of memory, from his exile in the Spanish island of Lanzarote. Edward Said's writings will guide the discussions on exile proposed in this work, as much as Philippe Lejeune's, whose writings appear in the dialogue between autobiography and memory.

KEYWORDS: José Saramago and autobiography; Literature and memory; Literature and exile. 
Os Cadernos de Lanzarote, diários escritos por José Saramago durante aproximadamente cinco dos quase vinte anos em que viveu nas Canárias, constituem documento sui generis no tocante à face autobiográfica da produção literária do português. Reconhecido pela escritura de seus romances, Saramago registra nos cadernos sua vida de homem afastado de Portugal, quando no ano de 1992 escolheu o isolamento (ou seria "exilamento"?) ao instalar-se na inóspita região vulcânica que dá nome aos diários, cercada de montanhas arenosas onde "não há estrada, nem caminho, nem trilha." (SARAMAGO, 2010, p. 165). Vivendo em Lanzarote, o escritor desenvolveria uma estratégia por meio da qual é apresentada uma coletânea que oferece aos leitores a oportunidade de apreciarem sua tarefa cotidiana de escrita. Saramago transita pelos meandros da política portuguesa, da crítica literária, das relações com os afetos e desafetos da sociedade lusa, desenvolvendo uma espécie de literatura cuja marca fundamental parece residir no tratamento que ele dedica à memória de sua trajetória como cidadão português, além de apresentar-se como exercício de aprendizado do exílio para o qual o escritor se retirou, provocado a princípio (ao menos em termos factuais) por ocasião da polêmica de 1992, quando, por decisão do governo português, chefiado pelo primeiro-ministro António Cavaco da Silva, O Evangelho Segundo Jesus Cristo fora proibido de ser laureado com o Prêmio Literário Europeu por, segundo o ministro, ofender as crenças religiosas do povo português.

\section{O EXÍLIO E O INTELECTUAL}

O exílio é tema tratado amiúde no século XX, especialmente pela literatura e pela filosofia (leiam-se aqui suas ramificações: antropologia, sociologia...) que nas últimas décadas, talvez por se tratar de uma marca resultante dos regimes governamentais totalitários que se instauraram sobremaneira no período pós-guerra, deram-lhe espaço cada vez mais privilegiado em ambiente de discussão intelectual.

Porém, parece necessário escrever sobre o exílio com certa cautela, não tomando-o como um tema unívoco e autocentrado, já que essa postura poderia incorrer em tremendo equívoco. Essa experiência (a do exílio) deve ser percebida e tomada em suas particularidades, sobremaneira as causais. $\mathrm{O}$ exilado assume esta condição de apartado de sua terra natal para morar (nem sempre "habitar") em outro lugar que não aquele de origem. Contudo, nem sempre o faz porque é obrigado, impelido por forças maiores, quer de poder político, quer institucional, ou até mesmo por razões econômicas. Por vezes, o exilado recorre ao afastamento de seu lugar natalício, posto que este não lhe oferece mais o espaço para que se manifeste como deseja, ou ainda, sente-se o exilado alijado da sua própria casa porque ela já não mais o acolhe como filho dileto, ou não reconhece nele um representante digno da identidade patriótica que representa os interesses e as ideologias nacionais. 
Nessa aproximação do exílio com a ideia de exercício de liberdade daquele que ora se coloca "voluntariamente" na condição de exilado, Edward Said é aqui citado por representar a personificação de tal atitude. Nascido em Jerusalém, filho de árabes cristãos e com cidadania norte-americana, Said cresceu no Egito e no Líbano e estudou em instituições britânicas, tendo aprendido inglês e árabe ao mesmo tempo. Após ter cursado universidade nos Estados Unidos, ele ganhou influência no meio acadêmico, especialmente no âmbito dos estudos culturais, lecionando literatura comparada e teoria literária na Universidade de Columbia, em Nova York. Além disso, ficou conhecido internacionalmente como um dos principais intelectuais e ativistas políticos da causa palestina.

Como se pode notar, essa breve descrição biográfica problematiza a ideia de pertencimento a uma nacionalidade sólida e coerente. Escreveu Said em Fora do lugar:

Às vezes me sinto como um feixe de correntes que fluem. Prefiro isso à ideia de um eu sólido, à identidade a que tanta gente dá importância. [...] Com tantas dissonâncias em minha vida, de fato aprendi a preferir estar fora do lugar e não absolutamente certo. (SAID, 2004, p. 429)

A tentativa de resgate de elementos que esboçam uma atmosfera de nação é um caminho tomado por sujeitos exilados. Sob o prisma das reflexões de Said, “o exílio é uma solidão vivida fora do grupo: a privação sentida por não estar com os outros na habitação comunal” (SAID 2003, p. 50). O porto seguro procurado por aqueles que se encontram nessa condição tem as cores do nacionalismo, que imprime uma poética do pertencer para resgatar o lugar do qual um sujeito se descolou. Para Said, o exílio "é uma fratura incurável entre um ser humano e um lugar natal, entre o eu e seu verdadeiro lar" (SAID, 2003, p. 46), e acionar raízes é uma forma de tentar resgatar o senso perdido de pertencimento; todavia, como nos lembra Gyorge Lúkacs, essa perda incide sobre a condição do sujeito moderno após a travessia da era helênica.

Parece-nos bastante pertinente, pois, aproximar José Saramago de Edward Said, particularmente em consonância com as colocações do israelense em seus livros Reflexões sobre o exílio e outros ensaios e Representações do intelectual - As conferências Reith de 1993. Ainda que Edward Said concentre sua análise do exílio na situação da "expatriação forçada", tratando inclusive o problema como sendo mais contundente no âmbito da esfera coletiva das denominadas "minorias", o diálogo faz-se possível; é preciso considerar, para tanto, a existência de um aprendizado do exílio, que se desenvolve naqueles que vivem afastados da terra natal, quer pela força, quer por livre escolha ou por contingências políticas que escapam às duas primeiras motivações. Esse saber inclui uma educação sentimental que facilita o aprendizado de si mesmo e, talvez, promove um aprendizado mais amplo sobre o lugar de origem, por ocasião do que Said denominou 
contrapuntual awereness, conceito que será retomado adiante. Saliente-se que Said também reflete sobre a condição do viajante, e as intersecções possíveis entre essa condição e a do exilado, que obviamente são dialógicas e integram o saber acerca do exílio.

José Saramago, durante os últimos anos de sua vida, estabeleceu com Portugal uma relação de exilado quando decidiu expatriar-se ainda no ano de 1993. O escritor provoca por ele mesmo, em si mesmo, a fratura incurável mencionada por Said, que consiste na ruptura entre o ser humano e seu lugar natal, entre um "eu" e seu verdadeiro lar. É, aparentemente, uma tristeza essencial que não pode ser jamais superada, porque, segundo Said:

O exílio, ao contrário do nacionalismo, é fundamentalmente um estado de ser descontínuo. Os exilados estão separados das raízes, da terra natal, do passado. [...] os exilados sentem uma vontade urgente de reconstituir suas vidas rompidas e preferem ver a si mesmos como parte de uma ideologia triunfante [...]. (SAID, 2003, p. 50)

O estado de descontinuação apontado por Said aparece em Saramago como uma tentativa de, afastado da terra pátria, afirmar seu antieuropeísmo pela denúncia da desnaturalização que Portugal sofreria nos anos que se seguiram a sua mudança para Lanzarote, insistindo em desaprovar a apatia social e a ausência de senso autocrítico, o que viria a constituir um processo de conformismo e declínio. Embora suas convicções iberistas tenham lhe acarretado desqualificações várias por parte dos portugueses, uma vez que ele mesmo declarara ter perdido o sentimento idealizador da pátria, Saramago não deitava de lado o orgulho de ser português, ainda que tenha abandonado a partir de 1989 o país como roteiro de suas lusitanas histórias. Já residindo nas Canárias o autor oportunizou uma leitura de Portugal por meio de seus diários, nos quais o compromisso em espicaçar as consciências, exercendo seu papel de intelectual das letras, constituiu uma das características dessa literatura "de exílio", sem que seja esquecida a dor da descontinuação. Dois anos antes de se instalar em Lanzarote, declarava o autor a um periódico espanhol:

Não sei até que ponto este país [Portugal] precisa de mim, mas sei até que ponto eu preciso dele. Este país agrada-me até aquilo que tem de menos bom. Há uma relação muito mais importante do que isso que se chama patriotismo; é uma relação carnal, de raízes. Tenho-a. Procuro, sobretudo, saber quem sou, nunca como um ser individual, mas como alguém que está nesta coisa que é um povo e uma história. (SARAMAGO, 2010, p. 99-100)

Nunca pareceu ser intenção de Saramago mudar-se de Portugal. Intelectual das letras, intervinha com frequência nas discussões que tinham a política interna portuguesa como foco, bem como a inserção do país no cenário político europeu. Não obstante, seus romances, quase sem 
exceção, ofereciam ao leitor atento um panorama da história de Portugal, tendo por princípio a crítica e o inconformismo que lhe eram peculiares também no exercício de sua cidadania e sua inserção no espaço público. No exercício de seu papel de intelectual, transitava entre a representação do intelectual orgânico gramsciano e aquela do intelectual universal, assim como o denominava Foucault, o qual, segundo Said (2005, p. 26), paulatinamente cederia lugar ao intelectual específico. $\mathrm{O}$ autor do Ensaio sobre a cegueira, obra escrita durante seu exílio em Lanzarote, jamais deixou de fora de sua obra ficcional a leitura crítica da sociedade portuguesa, inserida na problemática ibérica frente ao resto da Europa, sempre constituindo preocupação de Saramago no que poderia ser compreendido como uma maneira de ler Portugal que o aproxima, de certo modo, do pensamento ensaístico de Eduardo Lourenço.

O escritor, que, a propósito de exemplificação, desempenha nessa elaboração discursiva a intervenção inerente ao seu papel de intelectual português moderno, encontra também ressonância de sua atuação como crítico na obra de Edward Said. O inconformismo com as regras impostas pelo status quo; a constante necessidade de colocar as discussões em suspenso para que a concordância se opere em situação de maior igualdade entre os diferentes pares do jogo dialógico - tudo isso encontra eco em com Said quando o palestino afirma que o intelectual é, além de qualquer outro posicionamento possível ou caracterização mais pormenorizada, aquele que "questiona as normas vigentes; e isso porque precisamente as normas dominantes estão [...] ligadas à nação, e esta é sempre triunfalista, está sempre numa posição de autoridade, sempre exigindo lealdade e subserviência em vez de investigação" (SAID, 2005, p. 47). Cito Saramago:

Espalham por aí ideias sobre minha relação com o meu país que não estão corretas. Saímos de Lisboa [para a ilha de Lanzarote] em consequência de uma atitude do governo, não do país nem da população. Mas do governo, que não permitiu que meu livro [O Evangelho segundo Jesus Cristo] fosse inscrito num prêmio da União Europeia. Nunca tive problemas com o meu país, mas com o governo, que depois não foi capaz de pedir desculpas [...]. Mudei de bairro, porque o vizinho me incomodava. E o vizinho era o governo português. (SARAMAGO, 2008, p. 37).

A declaração de Saramago parece estabelecer uma espécie de paradoxo com a conceituação de Said citada no início desta elucubração sobre o a condição do exílio. Àquela fratura incurável entre a terra natal e aquele que a deixa contrapõe-se outro modo de ver o exílio, colocando-o numa circunstância não mais irremediável. O mesmo Said, que nas suas "reflexões" sobre exílio abordou de maneira contundente a ideia da separação entre cidadão e pátria, apontaria uma possibilidade de reconciliação desta condição, aparente refutação à sua própria tese. 
No capítulo três das Conferências Reith de 1993, afirma Said que a ideia difundida "de que o exílio significa um corte total, um isolamento, uma separação desesperada do lugar de origem", está "totalmente equivocada" (SAID, 2005, p. 56). A aparente contradição estabelecida por ele parece consistir no fato de que, ao mencionar essa 'fratura' nas Reflexões sobre $o$ exílio, não parecia o autor associar a condição de exílio à figura do intelectual. Nas conferências, contudo, parece ficar estabelecido o diálogo entre ambos, promovendo assim uma espécie de relativização que é perceptível, por exemplo, quando Said trata o exílio como condição profícua para a produção de discursos e prática de inserções de uma política da escrita que talvez não fosse possível fora dele. Ao se referir a Theodor Adorno, exemplifica o autor que "foi seu exílio americano que produziu sua grande obra-prima, Minima moralia" (SAID, 2005, p. 63).

Não cabe a ingenuidade de uma conclusão que leve a supor que somente no exílio é possível produzir-se uma grande obra. Tampouco, afirmar que qualquer condição de exílio é condição privilegiada para a confecção de uma reflexão superior sobre o que é habitar a pátria. O que talvez possa ser ensaiado é o argumento de que, no exílio, o intelectual se vale da condição de expatriado para desenvolver seu contrapuntual awareness, ou seja, uma tomada de visão privilegiada em relação ao lugar de origem possibilitada pelo deslocamento da percepção. Não seria confortável afirmar que só é possível produzir determinada literatura no exílio, por exemplo, a autobiografia. Mas é lícito ponderar que vários autores, quando em situação de exílio, viram-se impelidos a escrever suas memórias, seus testemunhos, ou mesmo seus diários. Cada estimulado por sua especificidade de cisão (Gramsci pela reação à política de Mussolini, Graciliano Ramos por sua provável relação com a Intentona Comunista, Saramago por seu inconformismo com a postura da Igreja Católica em Portugal), cada um à sua maneira, percebeu durante a experiência do exílio a condição necessária ao desenvolvimento de uma nova maneira de ver, sentir, dizer sobre o si mesmo e sua relação com a "casa", ou mesmo sobre a relação estabelecida entre si, a nova morada e como a antiga casa lhe parece agora.

\section{O DIÁRIO COMO ESCRITURA DA MEMÓRIA}

Jeanne Marie Gagnebin, em seu livro Lembrar escrever esquecer (2006), inicia o capítulo VII afirmando que há hoje uma grande preocupação com a questão da memória. Segundo a autora, "assistimos a um boom de estudos sobre a memória, desmemoria, resgate, tradições”. (GAGNEBIN, 2006, p. 97).

Mesmo afastados cronologicamente da afirmação da Gagnebin, essa tão atual literatura da memória também se insere nas discussões que envolvem o tema do exílio, especialmente quando tomada essa questão pelo viés da elaboração de uma escritura que se afirma pela apreensão de uma experiência que carece de relato, já que o silenciamento fora, durante 
a experiência, interposto entre o censor e o censurado, entre o torturador e o torturado, senhor e escravo, ou quantas mais dicotomias forem possíveis de exemplificação. Afirmou-se, pois, esse gênero do discurso (para usar conceituação bakhtiniana) por instaurar uma nova especificidade literária cuja matéria prima tem na constituição do relato, do testemunho, da representação da experiências-limite, a sua "pedra de toque". Essa literatura passou a ser denominada, a partir daquele recorte espaço-temporal, "literatura de testemunho". Marcio Selligman-Silva aponta que este gênero, instaurado na segunda metade do século XX, permite (para além de outras questões) a elaboração de rediscussões sobre a escritura e os limites entre a ficção e o relato. Segundo o autor:

Esta crença em um gênero que poderia travar o que pode ser denominado de processo de ficcionalização, que considero inerente a toda narrativa, parece-me questionável. [...] Equacionar ficção e mentira também é complicado, pois, além de a fantasia não ser necessariamente avessa à verdade, da mesma forma a mentira não existe dentro e fora da literatura. (SELLIGMAN-SILVA, 2006, p. 7)

Desse modo, as literaturas denominadas "de testemunho", pós Auschwitz ou, ainda, escrituras que procuraram dar conta do que em termos benjaminianos poderia ser chamado de "rememoração", constituíram na segunda metade do século XX o que nas palavras da psicanalista argentina Eva Giberti consistia na tentativa de fundar uma "memória ativa", estatuto que aponta para uma memória que se coloca a serviço da justiça, servindo-se do passado sob o domínio da vida. De acordo com a concepção da psicanalista, essa memória se constitui por meio de uma ação coletiva, que se efetiva através da reclamação, função maior da memória que não cessa de se fazer presente. De acordo com Giberti:

La memoria conserva la temperatura y la vibración imprescindibles para salir al rescate de lo sucedido porque los seres humanos podemos quedar prisioneros de esa realidad corrompida en la que, por efectos del tempo y el olvido, se desactivan los recuerdos de lo acontecido [...] (GIBERTI, 1992, p. 12)

Contudo, os diários escritos por Saramago não podem ser inscritos de maneira definitiva nessa modalidade que reclama o passado a serviço de uma ética que tem nas minorias o seu horizonte de representação. $\mathrm{O}$ autor, que possui apenas um livro publicado como que representativo do que ora se denomina "literatura de memória" (As Pequenas Memórias, 2006), reclama em seus diários as páginas mais autobiográficas de que se têm notícia no amplo universo de produção ficcional do escritor. Os Cadernos de Lanzarote, escritos entre os anos de 1993 e 1997, representam sua literatura autobiográfica, que o próprio autor nomeia “diários", fragmentos de um presente contínuo em que Saramago dá a ver o exercício de escrita de alguns dos seus futuros livros, bem como exerce aquilo que melhor o ca- 
racteriza como um intelectual moderno, a saber, a incapacidade de se conformar. O próprio Saramago, numa entrevista à então futura mulher Pilar Del Río, em 2001, dizia: "Aparentemente, sim, estou inteiro [...]. Mas quem me conhece bem sabe que sangro por dentro. [...] Sou em carne e em espírito um grito de dor e indignação". (SARAMAGO, 2010, p. 13, grifo nosso)

Além dessa questão que diz respeito à uma estreita relação entre a escrita autobiográfica e o dever intelectual de Saramago, chama a atenção o fato de o escritor não ter escrito "memórias", mas "diários". Iniciando o diário I com a epígrafe gassetiana "eu sou eu e minha circunstância" (SARAMAGO, 1997, p. 9), o autor já dá uma pista do que virá pela frente. Paradoxalmente, ao afirmar que "ninguém escreve um diário para dizer quem é" (SARAMAGO, 1997, p. 9), o escritor remete a dois conceitos que estão diretamente interligados ao gênero a que se propõe a partir de 1993: o de autobiografia e o de ficção.

Em O pacto autobiográfico (2008) Philippe Lejeune ensaia uma resposta à questão: quais seriam os limites entre a ficção e a autobiografia? Segundo Lejeune, a priori, a autobiografia apresenta-se como um texto literário, por constituir-se fundamentalmente de uma "narrativa retrospectiva em prosa, que uma pessoa real faz de sua própria existência, colocando o acento sobre sua vida individual, em especial a história de sua personalidade" (LEJEUNE, 2008, p. 49). Quando alguém escreve uma autobiografia, entre o escritor e o leitor é realizado um pacto, no qual se estabelece uma espécie de jogo da verdade, fundado na contribuição do leitor, sua aceitação integral ou não do pacto. Um contrato passa a figurar a partir desse momento.

Afirma ainda o autor que a produção autobiográfica tem como fator determinante o interesse no tempo presente, este ligado ao momento de sua produção. Contudo, de acordo com Lejeune, seria necessário um distanciamento histórico entre o momento de escritura e o evento que a motivou, uma vez que a assimilação do passado pelo presente necessitaria de maturação e, por fim, compreensão das próprias experiências para que seja possível transformar essa experiência em conhecimento. Complementa o autor:

O que chamo de autobiografia pode pertencer a dois sistemas diferentes: um sistema referencial "real" (em que o compromisso autobiográfico, mesmo passando pelo livro e pela escrita, tem valor de ato) e um sistema literário, no qual a escrita não tem pretensões à transparência, mas pode perfeitamente imitar, mobilizar as crenças do primeiro sistema. Muitos fenômenos de ambiguidade ou de mal-entendido vêm dessa posição instável. (LEJEUNE, 2008, p. 57).

Lejeune, ao tratar do conceito, da representação e dos limites da autobiografia, dedica um capítulo especial, aparentemente escrito a posteriori, à conceituação do "diário". Permite-se fazer aqui um pequeno excurso 
sobre essa modalidade, para tentar mostrar especificamente como esse gênero se aproxima da ideia da escrita autobiográfica em José Saramago nos Cadernos de Lanzarote.

Para Lejeune, a autobiografia estabeleceria uma relação mais proximal com a ficção, enquanto o diário apresentaria certa tendência para a representação da verdade: "autobiografia vive sob o feitiço de ficção, o jornal tem uma queda pela verdade" (LEJEUNE, 2008, p. 205). Parece que o autor procura manter bem separados os campos de força da ficção e da autoescritura. "Eu aprecio a autobiografia, eu adoro ficção, eu não gosto de sua mistura" (LEJEUNE, 2008, p. 206). Segundo ele, o diário seria um bom meio para se atingir tal objetivo. O diário é, segundo ele, 'antificção', o que soa um tanto suspeito, uma vez que somos, segundo Ricouer, hommes-récits (homens-narrativas) e que a ficcionalização, o "fingir" pessoano é inerente a toda e qualquer literatura.

Por outro lado, é inegável que seja possível identificar no diário algo como as marcas e traços do presente de sua escritura. O diário produz páginas que se embaralham com a vida de seu autor-protagonista, já que, segundo Lejeune, constitui ele uma "série de vestígios" (LEJEUNE, 2008, p. 260). Nele, somos tocados, segundo Marcelo Selligman-Silva "pelo ar que o personagem respirava. Tendemos e ver nele um testemunho, ou seja, um indice, metonímia, e não uma metáfora, que é tradução imagética e mais distanciada dos fatos arrolados". (SELLIGMAN-SILVA, 2006, p. 214).

Além disso, há de se remeter à força discursiva do diário que reverbera em grande parte da literatura, sobretudo desde o Romantismo, como se pode verificar em Goethe, Graciliano Ramos, Gramsci entre tantos outros autores. Seu convencimento estético é reforçado por um elemento ético. Substituindo uma ideia corriqueira que vê no diário uma representação e imitação dos fatos da vida, aprendemos agora a ler, nestas páginas, fragmentos de um presente que se amontoa diante de nós: de um passado que não passou. Pretérito do presente, presente do passado. Resultado de um trabalho que arranja e organiza os vestígios.

Além disso, para Lejeune, ao contrário do que afirma Saramago (daí o caráter ambíguo do diário), é para si mesmo que se escreve um diário. Para o autor "É [...] para si que se escreve um diário: somos os próprios destinatários no futuro. Quero poder [...] reencontrar os elementos de meu passado: os que anotei e os que associarei a eles em minha memória”. (LEJEUNE, 2008, p. 261).

É nesse ponto que nota-se uma imbricação complexa entre a questão da memória e do diário enquanto gêneros. A memória, como atualização do passado para reconstituição da experiência, pode se servir do diário, que nesse caso funciona como espécie de artefato, cuja funcionalidade recai em fixar o tempo presente, agora passado, a fim de que não se esvaneça completamente, além de prevenir um esvanecimento também do futuro. Tomada a categoria da memória como elemento de alta complexidade, dadas todas as searas abertas por conta das dicotomias resultantes 
de seu questionamento - memória versus reminiscência; memória versus hábito - além das categorias de tempo, espaço e contexto que estão implicadas em sua apreensão, recolhe-se este breve ensaio ao trabalho com a categoria do diário, afinal, justificada por encontrar-se inscrita no universo da produção autobiográfica de Saramago.

Nos Cadernos, Saramago exercita não só a escritura de percepções do seu cotidiano, mas ensaia reflexões sobre os temas que são trazidos à baila deste breve estudo.

A começar pela relação com o tempo, os escritos que compõem os Cadernos são datados, retomando a ideia de Lejeune de que, antes de qualquer coisa, o diário é constituído por uma "série de vestígios datados" (LEJEUNE, 2008, p. 259). Saramago escreve quase que diariamente, possibilitando a localização temporal, tanto dos acontecimentos relatados, bem como das divagações e rememorações. Além disso, Saramago utiliza seus diários para conservar a memória, sobreviver, desabafar, conhecer-se, deliberar, resistir, pensar, categorias apontadas por Lejeune como constitutivas da estratégia de escrita do gênero.

Para salientar algumas dessas categorias, selecionam-se aqui algumas passagens que estabelecem a relação do exílio de Saramago com a elaboração de sua escrita autobiográfica. A começar pelo tema da conservação da memória, Saramago ratifica o que já fora anteriormente salientado: seu caráter ambíguo e paradoxal. Lugar de desconfiança e de desconhecimento, ela foi assunto das divagações do autor no dia 07 de maio de 1993. A referência ao texto é extensa, porém é necessária a citação em quase sua totalidade de modo que se possa apreender mais amplamente a consideração do autor. Cito:

Sobre a memória: "A memória é um espelho velho, com falhas no estanho e sombras paradas: há uma nuvem sobre a testa, um borrão no lugar da boca, o vazio onde os olhos deviam estar. [...] recompomos uma imagem que nos seja possível reconhecer como ainda nossa, encadeável com esta que hoje temos, quase já de ontem. A memória é também uma estátua de argila. O vento passa e leva-lhe, pouco a pouco, partículas, grãos, cristais. A chuva amolece as feições, faz descair os membros, reduz o pescoço. Em cada minuto, o que era deixou de ser, e da estátua não restaria mais do que um vulto informe, se também em cada minuto não fôssemos restaurando, de memória, a memória [...]. (SARAMAGO, 1997, p. 32)

Não parecem essas linhas apenas divagações do escritor português sobre a memória. Constituem uma espécie de refutação contundente ao entendimento de Lejeune sobre o diário. Saramago, liricamente, reflete sobre a constituição da memória metaforizando-a, adentrando o terreno da alegoria para discorrer sobre uma categoria que naquele momento toma-se a si mesma como metaliterária, um exercício do exílio. 
Entre relatos estritamente rotineiros de sua participação em congressos, seminários, mesas-redondas, prêmios literários e convenções, Saramago faz dos seus diários um instrumento de seu exercício intelectual. Entre memória do passado remoto e constituição de uma futura memória do presente por meio da escritura dos diários, dedica-se ou autor à atividade literária escrevendo, pela primeira vez, de um lugar que não é o seu. Lanzarote passa a ser a casa que lhe permitirá voltar a 1966, ano em que publicara os Poemas Possíveis, tomando a investida de retorno ao passado para avaliar seu papel como escritor português. Tomada assim a categoria do pensamento, referida por Lejeune como uma das funcionalidades da escritura cotidiana, Saramago recorre à memória de certo poema que se salvara do "caixote de lixo", no qual tantos outros foram arremessados, para remeter-se à reflexão sobre o seu fazer literário. Saramago cita os versos, afirmando que:

[...] desse poema, as únicas palavras aproveitáveis, ou, para dizê-lo, doutro modo, aquelas que o puseram a salvo da tentação destruidora, são as seguintes: "Que quem se cala quanto me calei / não poderá morrer sem dizer tudo". Sobre o dia em que elas foram escritas passaram-se quase cinquenta anos, e se é certo lembrar-me ainda de como era o meu silêncio de então, já não sou capaz de recordar [...]. (SARAMAGO, 1997, p. 78).

O passado, ou a memória que se conserva dele continuam sendo matéria da escrita de Saramago nas páginas que seguem. Além da consciência que conserva sobre sua participação nas questões que envolveram a sociedade portuguesa, ibérica e europeia nos últimos decênios do século XX, Saramago, para além de sua intervenção como intelectual, parece também encetar sua pena na organização de um novo modus operandi relativo à sua atividade de escritor, que se apresenta materializada quando do seu deslocamento para Lanzarote. "Cada novo dia me aparece como um imenso espaço em branco e o tempo como um caminho que vai discorrendo lentamente." (SARAMAGO, 1997, p. 104), escreve em 19 de agosto de 1993, dia em que também se dá conta de que, ao contrário do que acontecia até então, a concomitância de dedicação à atividade de escrever, ao mesmo tempo e hora, obras diferentes parece um convite. Saramago comenta que, para além dessa convergência de processos criativos, parece-lhe a "potência memorizadora" assombrosa, uma vez que inesperada. A categoria da escritura concernente à escritura de diários pode, sem prejuízo, ser aqui referida. Cito:

Precipitam para mim como se irrompessem num quarto escuro e fechado onde, antes, não tivessem podido reconhecer-se uns aos outros como passado de uma mesma pessoa. [...] e agora se descobrem, cada um deles, condição de outro, e, todos eles, de mim. E o mais assombroso é a nitidez com que, letra a letra, se estão reconstituindo na minha cabeça as palavras e os rostos, as paisagens e os ambientes, os nomes e os sons desse tempo longínquo que foi o da minha infância [...]. (SARAMAGO, 1997, p. 105). 
É lícito considerar que a partir do momento em que Saramago se coloca na posição de exilado, torna-se possível a elaboração de um discurso autobiográfico, no qual o testemunho abre espaço ao relato diário das experiências comezinhas, cotidianas, bem como, em suas descontinuidades, alusões e lacunas, convida a memória a se apresentar como discurso velado, ora revelado? Qualquer conclusão definitiva sobre o exposto incorreria em presunção. Contudo, há de se considerar a possibilidade de ensaiar-se a relação de causalidade, estímulo ou abertura de espaço à escrita autobiográfica a partir de uma experiência de expatriamento, exílio ou deslocamento do horizonte de expectativa. É nesse sentido, portanto, que José Saramago, pela escritura de seus diários, inscreve-se como escritor autobiográfico, mesmo levando-se em consideração as já mencionadas peculiaridades conceituais que envolvem o amplo espectro da literatura de memória no século XX, suas dicotomias e contrassensos. Saramago residira em Lanzarote por aqueles anos, porém, no sentido que propõe Hölderlin em seu famoso poema "Poeticamente o homem habita...", nunca deixaria de "habitar" Portugal.

\section{REFERÊNCIAS BIBLIOGRÁFICAS}

GAGNEBIN, Jeanne Marie. Lembrar escrever esquecer. São Paulo: Editora 34, 2006.

GIBERTI, Eva. Memoria Activa. Página 12, dic. 1992. Disponível em: $<$ http:/spot.net.ar/evagiberti/artículos $>$.

LEJEUNE, Phillipe. O pacto autobiográfico: de Rousseau à internet. Belo Horizonte: Editora UFMG, 2008.

SAID, Edward W.. Representações do intelectual: as Conferências Reith de 1993. Trad. de Milton Hatoum. São Paulo: Companhia das Letras, 2005.

. Fora do lugar: memórias. Tradução: José Geraldo Couto. São Paulo: Companhia das Letras, 2004.

. Reflexões sobre o exílio e outros ensaios. Tradução: Pedro Maia Soares. São Paulo: Companhia das Letras, 2003.

SARAMAGO, José. Cadernos de Lanzarote. São Paulo: Companhia das Letras, 1997.

. A Humanidade não merece a vida. In: Folha de São Paulo, São Paulo, em 29 de novembro de 1998.

. As palavras de Saramago: catálogo de reflexões pessoais, literárias e políticas. Fernando Gómez Aguilera (sel. e org.). São Paulo: Companhia das Letras, 2010.

SELLIGMAN-SILVA, Márcio (org.). Palavra e imagem: memória e escritura. Chapecó: Argos, 2006. 